\title{
Critical Care Aspects of Gallstone Disease
}

\author{
Piero Portincasa1* Emilio Molina-Molina1\#, Gabriella Garruti², David Q.-H. Wang ${ }^{3}$ \\ 1 Clinica Medica "A. Murri", Department of Biomedical Sciences \& Human Oncology, University of Bari Medical \\ School, Bari, Italy \\ 2 Section of Endocrinology, Department of Emergency and Organ Transplantations, University of Bari "Aldo Moro" \\ Medical School, Piazza G. Cesare 11, 70124 Bari, Italy \\ 3 Department of Medicine, Division of Gastroenterology and Liver Diseases, Marion Bessin Liver Research Center, \\ "Albert Einstein" College of Medicine, Bronx, NY 10461, USA
}

\begin{abstract}
Approximately twenty per cent of adults have gallstones making it one of the most prevalent gastrointestinal diseases in Western countries. About twenty per cent of gallstone patients requires medical, endoscopic, or surgical therapies such as cholecystectomy due to the onset of gallstone-related symptoms or gallstone-related complications. Thus, patients with symptomatic, uncomplicated or complicated gallstones, regardless of the type of stones, represent one of the largest patient categories admitted to European hospitals.
\end{abstract}

This review deals with the important critical care aspects associated with a gallstone-related disease.

Keywords: bile, biliary colic, biliary secretion, cholecystectomy, cholecystitis, choledocholithiasis, cholesterol crystallization, CT scan, ERCP, MRCP

Received: 5 December 2018 / Accepted: 8 January 2019

\section{INTRODUCTION}

The prevalence of gallstones in adults is about twenty per cent in developed countries [1], with a yearly increasing incidence rate of 0.60-1.39\% [2]. In Europe, gallstone hospitalisation is one of the most common gastrointestinal diseases [3]. The prevalence of gallstones increases with age, and is invariably higher in women than in men [4]. Gallstones, which grow in the gallbladder and bile ducts, present as different sized solid conglomerates, consisting mainly of cholesterol monohydrate crystals, calcium bilirubinate, mucin gels, and proteins. Gallstones are classified according to their chemical composition as (1) pure cholesterol (>75\%), (2) pure pigment, and (3) mixed stones. The latter contains $<75 \%$ cholesterol plus varying amounts of bilirubin salts and calcium. In westernized countries, cholesterol gallstones represent about $75 \%$ of stones, whereas black pigment stones represent about 20\%, and brown pigment stones only about 5\% [4-7] (Figure $1)$.

The rising prevalence and incidence of cholesterol gallstones parallel the concomitant rise of several metabolic abnormalities, such as insulin resistance and type 2 diabetes, expansion of visceral adiposity due to over- weight and obesity, and overall metabolic syndrome (MetS) [8,9].

The study of the natural history of gallstones shows that patients with gallstones remain asymptomatic in about $80 \%$ of the cases, a condition defined cholecystolithiasis [10-14]. Symptomatic gallstones or gallstone disease, by contrast, refers to gallstones causing symptoms without complications, i.e., uncomplicated biliary colic, or complicated asymptomatic gallstone disease.

The incidence of symptomatic gallstones is low, i.e., between $1-4 \%$ yearly $[10,15]$. Studies found that symptoms appear within five years in about $10 \%$ of patients, and within twenty years in about $20 \%$ of patients [16]. When symptoms occur, patients are liable to the risk of recurrent symptoms or complications. A previous survey by the National Cooperative Gallstone Study found that about $70 \%$ of symptomatic patients suffer from recurrent symptoms within two years of the initial episode [17]. In patients who develop an episode of biliary colic, the risk of requiring an emergency procedure increases with time, i.e., from less than $1 \%$ before week twenty to about $6 \%$ at weeks $40-52$ [18].

Thus, about $20 \%$ of gallstone patients require appropriate medical or surgical procedures such as cholecys-

\footnotetext{
Correspondence to: Piero Portincasa, Clinica Medica "Augusto Murri", Department of Biomedical Sciences and Human Oncology, University of Bari Medical School - Piazza Giulio Cesare 11 70124 Bari - Italy. E-mail: piero.portincasa@uniba.it 
tectomy or endoscopic due to the onset of gallstonerelated symptoms or complications [19-21].

\section{DYMPTOMATIC, UNCOMPLICATED GALL- STONE DISEASE}

\section{Biliary colic}

The diagnosis of this clinical event is based on several matters [22]. Non-specific symptoms, usually not related to the presence of gallstones include isolated heartburn, acid regurgitation, belching, nausea and vomiting, bloating, abdominal distension, chest pain, postprandial fullness and early satiety, and flatulence [23-26]. Visceral pain originates from the impact of the stone, or microlithiasis, or sludge in the cystic duct or the ampulla of Vater. This leads to the distension and contraction of the gallbladder and the biliary tract. The intermittent increase of the pressure in the gallblad-
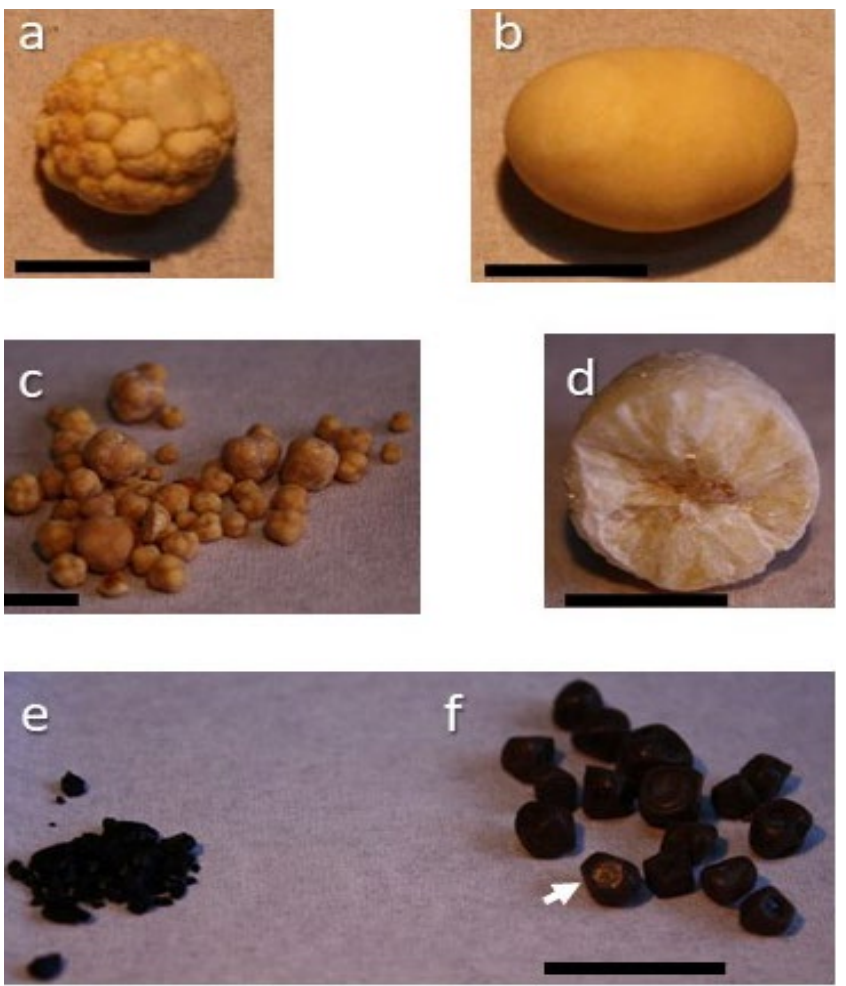

Fig. 1. Human gallbladder stones. Pure cholesterol stones with spherical shape and morular surface (a), oval shape and smooth surface (b), multiple stones (c). The cut surface is shown with a brownish centre and radial disposition of cholesterol monohydrate crystals (d). Pure pigment stones are shown as debris (e). Mixed stones are shown as multifaceted concernments (f). Note that the black pigment surface and the inner centre are made of a small amount of solid cholesterol crystals (arrow). Black horizontal line $=1 \mathrm{~cm}$. der activates visceral sensory neurons [27]. The pain is relieved if the stone travels back into the gallbladder lumen, or passes through the ampulla into the duodenum, or travels back into the common bile duct $[1,27]$. The pain develops as an intense and dull discomfort either continuous or intermittent with painful episodes ranging from hours to years [28]. The pain can be postprandial, usually occurring about two hours after a meal and especially after a heavy meal. However, a painful episode may be unrelated to a meal and can follow a distinctive timing and pattern for individual patients $[29,30]$. The intensity of pain is variable: it can increase and plateau to a high level $(9 \mathrm{~cm}$ on a $0-10$ $\mathrm{cm}$ scale). Some patients may ignore symptoms if the intensity is moderate.

The pain frequently starts in the right upper quadrant of the abdomen or at the epigastrium. These sites are T8/9 representative dermatomes. Chest pain onset is rare, but when it occurs, consideration should be given to a differential diagnosis of pain arising from cardiac or esophageal problems or a peptic ulcer. The duration of the pain is usually longer than 15-30 minutes and then slowly subsides. Special attention is required if the pain lasts several hours as this is often related to complications associated with gallstones.

During painful episodes, some non-specific gastrointestinal symptoms may occur. In about $60 \%$ of cases, pain radiates to the angle of the right scapula or shoulder, and in less than $10 \%$ of cases to the retrosternal area [27, 31]. In two-thirds of patients, a colicky pain may be associated with the urgency to walk [32]. Nausea and vomiting $[27,28,32]$, as well as diaphoresis may be related symptoms, while pain is usually not relieved by flatus or bowel movements [28]. Following a painful attack, physical examination may be normal or demonstrate the persistence of mild abdominal tenderness.

\section{Critical care aspects}

The early diagnosis of biliary pain is essential since the clinical picture represents a medical emergency and the clinician must avoid any delay in providing appropriate therapy. The definition of the characteristics of symptoms can help the diagnosis $[33,34]$. In the uncomplicated form, the physical examination of a gallstone patient can be negative, except for a residual abdominal tenderness. If the gallbladder wall is not swollen, the pain may be dull, with a negative Murphy's sign, because of the visceral origin [35]. If a biliary colic lasts longer than about three hours or is associated with 
more severe symptoms such as fever, nausea, vomiting, jaundice, and leukocytosis, the possibility of a gallstone-related complication exists.

Blood analyses can be abnormal during an attack of uncomplicated biliary colic or even between attacks. Analyses should be targeted to rule out acute cholecystitis, liver disease, significant inflammation pancreatitis and renal or ureteral involvement.

The therapy of biliary colic is based on fast-acting narcotic analgesics, with nonsteroidal anti-inflammatory drugs (NSAIDs) being the first-line therapy. There is evidence that NSAIDs are superior to antispasmodics $[36,37]$. The risk of complications such as acute cholecystitis, decreases with the initiation of early therapy [36, 38-40]. Opioids such as meperidine [41], butorphanol [42], or hydromorphone are valid alternative to NSAIDs. This is the best option in patients in which NSAIDs are contraindicated or ineffective [37]. Fasting is necessary during the period of pain, in order to avoid the release of endogenous hormones such as cholecystokinin, which can further stimulate the gallbladder contraction.

\section{SyMPtomatic, Complicated Gallstone DISEASE}

A subgroup of gallstone patients develop complications which include acute cholecystitis, gallstone ileus, chronic cholecystitis, choledocholithiasis, cholestatic jaundice, acute cholangitis, acute biliary pancreatitis, cholesterolosis, gallbladder polyps, gallbladder carcinoma, porcelain gallbladder, recurrent pyogenic cholangitis, and acalculous cholecystitis (Table 1).

Specific categories of patients are at increased risk of developing complications from gallstones. Patients

\section{Table 1. Complications of gallstones}

\section{Complications}

Acute cholecystitis*

Acute biliary pancreatitis*

Acute cholangitis*

Acute acalculous cholecystitis*

Biliary enteric fistula and gallstone ileus*

Choledocholithiasis

Cholestatic jaundice*

Cholesterolosis and gallbladder polyps

Chronic cholecystitis

Gallbladder carcinoma and porcelain gallbladder

Recurrent pyogenic cholangitis*

${ }^{*}$ Conditions characterized by critical care aspects. with diabetes mellitus have an increased risk of gangrenous cholecystitis [43], and patients with chronic haemolysis, i.e., hereditary spherocytosis or sickle cell disease, may develop pigment stones due to the accumulation of bilirubin in bile, and are more at risk of becoming symptomatic [22].

Native Americans [44], as well as patients with large gallbladder adenomas [45], pancreatic ductal draining into the common bile duct, porcelain gallbladder, or choledochal cysts, Caroli's disease, or carrying S. thyphi [46], are at increased risk of cholangiocarcinoma and gallbladder cancer. In this subgroup, a prophylactic cholecystectomy is advisable [47]. Also, obese patients undergoing gastric bypass surgery present with increased mobilisation of body cholesterol during weight loss. About one-third of patients develop cholesterol gallstones and are at risk of gallstone-related symptoms $[48,49]$.

\section{Acute cholecystitis}

In a patient with cholecystolithiasis, symptoms of acute calculous cholecystitis include gallbladder inflammation, pain in the right upper quadrant, fever and leucocytosis. Acute cholecystitis is the most frequent complication of gallstone disease occurring in up to $11 \%$ of gallstone patients over a median follow-up of 7-11 years [16].

Several predisposing conditions are associated with increased risk of acute cholecystitis [50-56], (Table 2) with complications including infection of the gallbladder with empyema, due to E. coli, Pseudomonas, streptococci, Klebsiella, and staphylococci, gangrene with perforation, pericholecystic abscess or peritonitis, in up to $20 \%$ of cases. These occur mainly in diabetes and older patients [43] or emphysematous cholecystitis [57] secondary to gas-producing micro-organisms such as the Clostridium welchii. Complications such as cholecystoenteric fistulas and gallstone ileus may occur following perforation of the gallbladder.

The diagnosis of acute cholecystitis is based on the history of risk factors, clinical manifestations [58, 59], imaging, and blood analyses which may include increased platelet count, bilirubin, blood urea nitrogen, creatinine, decreased prothrombin time-international normalised ratio, and abnormal arterial blood gas analysis $[60,61]$.

The choice of the best diagnostic imaging techniques for acute cholecystitis is given in Table 3. Abdominal 
Table 2. Conditions predisposing to increased risk of acute cholecystitis

\begin{tabular}{|c|c|}
\hline Acute non-biliary diseases & Immunocompromised illness \\
\hline Acute renal failure & $\begin{array}{l}\text { Infections (hepatitis B virus, ascariasis in developing coun- } \\
\text { tries) }\end{array}$ \\
\hline Age $>60$ years & Major surgery \\
\hline Biliary sludge & Female gender \\
\hline $\begin{array}{l}\text { Cardiovascular disease (history of ischemic stroke, cerebral } \\
\text { hemorrhage) }\end{array}$ & Multiple trauma \\
\hline Diabetes mellitus & Sepsis \\
\hline Gallstones & Severe burns \\
\hline Hormonal replacement therapy & Systemic vasculitis \\
\hline Hypertriglyceridemia & Total parenteral nutrition, long term fasting \\
\hline
\end{tabular}

ultrasonography is usually the first-choice technique. Additional imaging includes cholescintigraphy (HIDA) scan, magnetic resonance cholangiopancreatography, and computed tomography.

\section{Critical care aspects}

Aspects related to critical care become evident especially in the presence of complications developing as life-threatening conditions [62].

Management of acute cholecystitis is described in Figure 2 and is based on the work of Hirota et al. (2007) as expressed in the Tokyo Guidelines [58, 60, 61, 63].

Because of the potential life-threatening characteristics of acute cholecystitis, patients require careful monitoring and supportive care. Antimicrobial therapy is required, and in cases of moderate to severe intensity, the treatment plan is based on culture and sensitivity results $[58,64]$. In the most severe cases, when there is the presence of signs of severe inflammation, acute renal injury, shock, liver injury, and disseminated intravascular coagulation (DIC), treatment should also include monitoring of respiratory function and hemodynamics and appropriate organ support [61, 65]. Hirota $M$ et al. (2007) suggest that surgery should play an essential role in treating patients with acute cholecystitis. Early laparoscopic cholecystectomy is indicated in patients fulfilling the criteria for surgery during initial hospitalisation within one week. In this context, there is no increased rate of serious complications, as compared to delayed laparoscopic cholecystectomy. However, the hospital stay is shortened [66-70]. There is evidence that morbidity is higher if cholecystectomy is performed between seven and forty-five days compared with early cholecystectomy

Table 3. Imaging techniques for acute cholecystitis

\begin{tabular}{|c|c|c|}
\hline Technique & Major findings & Notes \\
\hline Abdominal ultrasonography & $\begin{array}{l}\text { Enlarged gallbladder size } \\
\text { Gallbladder wall thickening (>4mm) } \\
\text { Incarcerated gallstone(s) } \\
\text { Intraluminal debris echoes } \\
\text { Pericholecystic fluid collection or abscess } \\
\text { Positive "sonographic" Murphy sign } \\
\text { Sonolucent "double wall sign" }\end{array}$ & $\begin{array}{l}\text { First choice } \\
\text { Moderate sensitivity (88\%- } \\
90 \%) \text { and specificity (80\%) [63, } \\
122-124]\end{array}$ \\
\hline $\begin{array}{l}\text { Hepatobiliary scintigraphy } \\
\text { (technetium iminodiacetic } \\
\text { acid or hydroxyiminodiace- } \\
\text { tic acid) }\end{array}$ & $\begin{array}{l}\text { Compound given intravenously and excreted by the liver } \\
\text { Test is positive if the gallbladder is not visualized (i.e., cystic } \\
\text { duct obstruction due to edema by acute cholecystitis) [63] }\end{array}$ & $\begin{array}{l}\text { Highest sensitivity and specific- } \\
\text { ity }(\approx 90-95 \%)[123] \\
\text { Not easily available }\end{array}$ \\
\hline Computed Tomography (CT) & $\begin{array}{l}\text { Gallbladder wall edema } \\
\text { Pericholecystic fluid } \\
\text { Other complications [125] }\end{array}$ & $\begin{array}{l}\text { High sensitivity } 94 \% \\
\text { Low specificity } 59 \%[123,126]\end{array}$ \\
\hline $\begin{array}{l}\text { Magnetic Resonance } \\
\text { Cholangio-Pancreatography } \\
(\mathrm{MRCP})\end{array}$ & Gallstones are likely passed in the common bile duct [127] & $\begin{array}{l}\text { Moderate accuracy [123] } \\
\text { Not easily available } \\
\text { Under evaluation }\end{array}$ \\
\hline
\end{tabular}




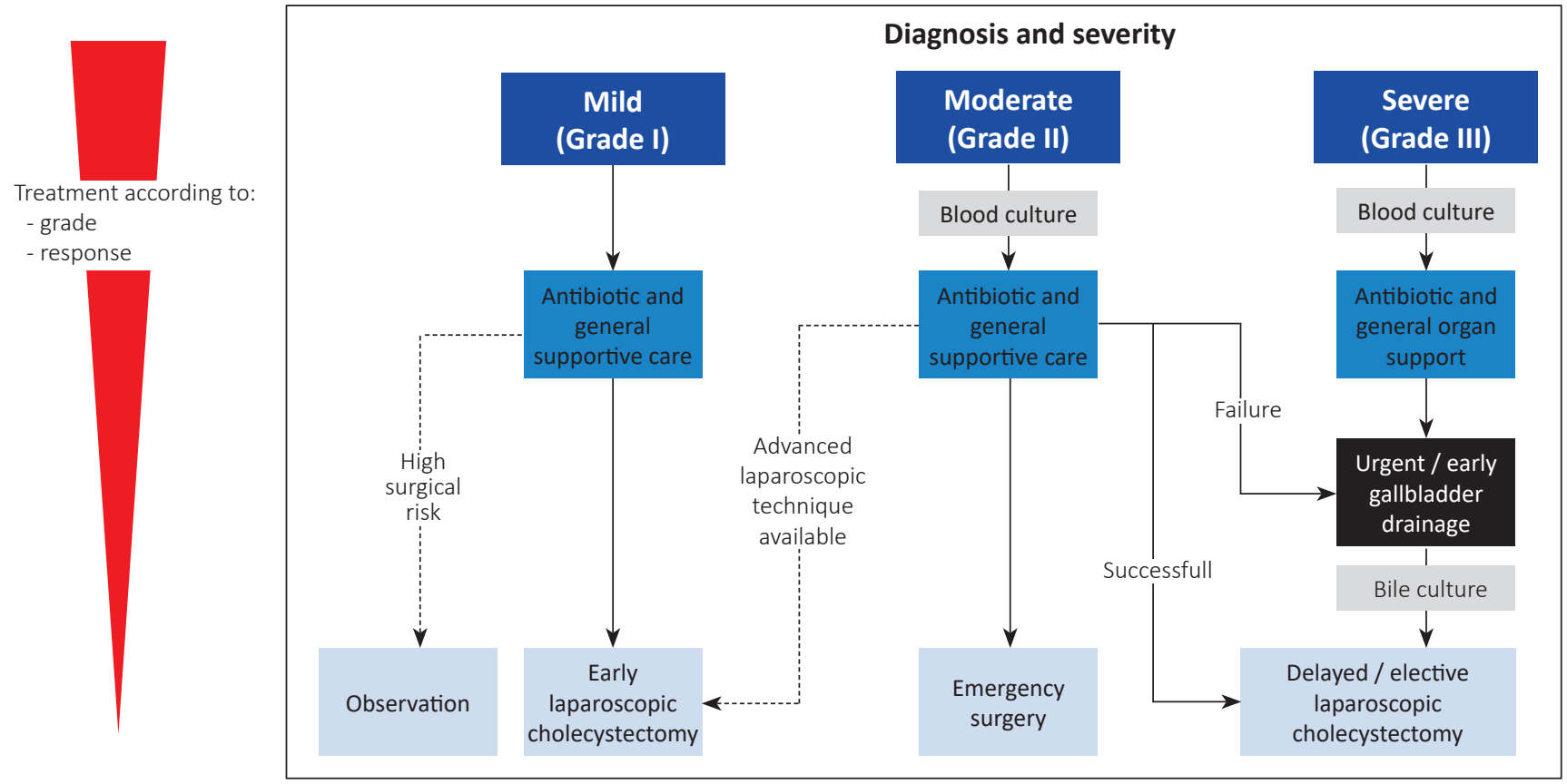

Fig. 2. Algorithm of the management of acute cholecystitis

[71]. Thus, when early cholecystectomy is not possible because of late diagnosis or high risk of surgery, it is advisable to delay cholecystectomy for another six weeks.

When patients with acute cholecystitis are too ill and show organ dysfunction or are considered to be non-responsive to initial medical treatment, therapy includes biliary drainage such as percutaneous transhepatic gallbladder drainage or open cholecystostomy and drainage, as well as percutaneous gallstone extraction, or delayed cholecystectomy. Endoscopic nasobiliary gallbladder drainage is an option in critically ill patients unfit for urgent or early cholecystectomy.

\section{Biliary-enteric fistula and gallstone ileus}

In a small subgroup of less than $0.5 \%$ of patients who undergo recurrent episodes of cholecystitis, there is the risk of developing biliary-enteric fistula following the perforation of the gallbladder into the intestinal lumen. The fistula is most often cholecystogastric, cholecystoduodenal or cholecystocolonic.

\section{Critical care aspects.}

Following the development of an enteric fistula, stone(s) may enter the bowel. A potential complication arises if the stone impacts the ileocecal valve, a condition causing the gallstone ileus. The clinical picture may present as mechanical bowel obstruction associated with a high rate of morbidity and mortality in elderly patients [72].

\section{Cholestatic jaundice}

Stones found in the common bile duct can be part of either primary or secondary choledocholithiasis, the latter being due to the migration of gallstones from the gallbladder into the common bile duct. The stone can cause bile duct obstruction, a condition leading to cholestatic jaundice which is associated with increased serum conjugated and unconjugated bilirubin [73].

\section{Critical care aspects}

The Mirizzi syndrome occurs when a stone is impacted in the cystic duct or the Hartmann's pouch, leading to compression and obstruction of the common hepatic duct or common bile duct [74], with the possible development of a cholecystoenteric fistula progressing to gallstone ileus.

\section{Acute cholangitis}

Acute cholangitis also named ascending cholangitis, occurs because of bacterial translocation from the intestine, vascular and lymphatic system. Predisposing conditions are bile stasis and infection in the biliary tract. Biliary stones represent the most frequent cause of biliary obstructions, ranging from 30 to $70 \%$. Other non-stone related conditions, besides bile duct stents leading to increased risk of acute cholangitis, are benign biliary strictures and tumors. 


\section{Critical care aspects}

Acute cholangitis is a clinical picture ranging from mild to life-threatening. The clinical diagnosis is suspected in a patient with fever, abdominal pain, and jaundice (the Charcot's triad). Essential laboratory tests include complete blood count, electrolytes, a metabolic panel, prothrombin time (PT), and PT-international normalised ratio. Blood cultures are required when cholangitis is suspected; the result can allow direct antibiotic therapy. Cultures can also be obtained from bile or stents removed at ERCP. The grade of disease severity depends on evidence of systemic infection and cholestasis, imaging (abdominal ultrasound, CT findings, or MRCP for finding dilatation of the common bile duct and evidence of stones), and dysfunction of different organs/systems $[61,75,76]$. In selected cases, i.e., patients cannot undergo MRCP but have evidence of biliary obstruction and increased serum conjugate bilirubinemia, ERCP or endoscopic ultrasound are required for confirmation of the diagnosis and biliary drainage. Management of acute cholangitis is based on the grade of disease severity that is usually classified as severe, moderate, and mild (Figure 3 ). The therapy requires some combination of medical therapies, includ- ing hydration, correction of electrolyte disorders, pain control by analgesics, follow-up for organ dysfunction and septic shock, and a series of antibiotics active against enteric streptococci, anaerobes, and coliforms. The choice of antibiotics relies on the possibility that the infection is community-acquired or healthcare-associated, individual risk factors and additional risk of antibiotic-related side effects. Initial empiric antibiotic regimens include single-agent regimens, i.e., piperacillin-tazobactam, or combination regimens, i.e., cefuroxime, ceftriaxone, ciprofloxacin, or levofloxacin plus metronidazole. The antibiotic treatment is subsequently tailored, depending on the results of culture and susceptibility, and continued for 4-5 days [77]. Additional management includes organ support and additional procedures which include endoscopic, percutaneous and surgical drainage $[60,63,65,78,79]$. A particular concern is that of pregnant women with acute cholangitis. In general, these patients are managed in the same way compared to non-pregnant women, i.e., with antibiotics and biliary drainage. The choice of the antibiotic, however, is tailored to the possibility of foetal toxicity. If fluoroscopy is required, foetal shielding is used. The mortality rates have dropped from more

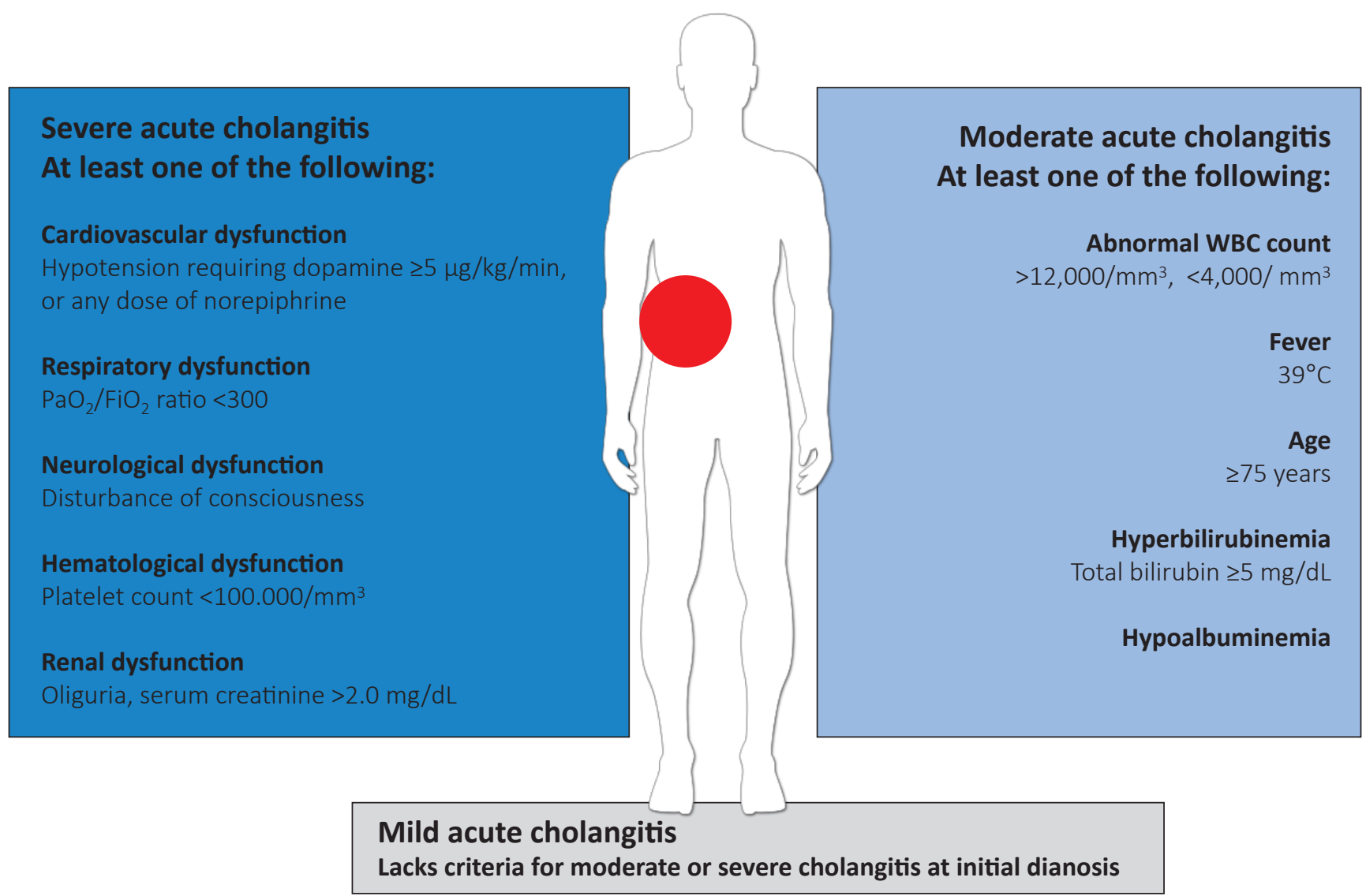

Fig. 3. Definition of severity of acute cholangitis. 
than $50 \%$ to about $11 \%$, due to overall improved management of disease [80]. However, a higher mortality rate $(20-30 \%)$ is reported in patients with severe acute cholangitis [81].

\section{Acute biliary pancreatitis}

Gallstones account for 35\%-40\% of patients with acute pancreatitis $[82,83]$, and the risk increases further in patients with small gallstones [84].

Bile reflux into the pancreatic duct is a true predisposing factor for biliary pancreatitis; the three leading causes include temporary or constant obstruction due to ampullary gallstone(s), and oedema secondary to gallstone passage [85]. Clinical signs occur when a gallstone is impacted within the ampulla of Vater, leading to occluding drainage of the pancreatic duct.

\section{Critical care aspects}

Acute biliary pancreatitis can be a life-threatening condition and can be associated with increased morbidity, making early recognition of the condition of paramount importance. Patients develop a steady pain in the mid-epigastrium or right upper quadrant. In some cases, the pain is diffuse or in the left side. It reaches maximum intensity in about twenty minutes and can last for several days, with possible band-like radiation onto the back. Bending forward can give some pain relief. Biliary colic may occur before acute pancreatitis or may proceed it. The associated symptoms are agitation, nausea and vomiting for several hours [86-90]. In addition to an increase in serum amylase and lipase levels, an elevated serum alanine aminotransferase (ALT) concentration of more than three times is highly suggestive of a biliary etiology. Patients hospitalization for gallstone pancreatitis are at low risk of stones in the common bile duct if bilirubin levels normalized after two days of admission [91]. The use of abdominal ultrasound is often the first line of the investigation, but it should be noted that it has a low sensitivity for the detection of common bile duct stones. Ultrasonography, however, reliably identifies common bile duct dilation, a finding which is frequently associated with choledocholithiasis. Additional imaging studies include an abdominal CT scan and MRCP, both of which can detect gallstones or dilatation of the common bile duct due to choledocholithiasis [92-96].

For the identification of bile duct stones in patients with gallstone pancreatitis without cholangitis or biliary obstruction and at risk of choledocholithiasis, endoscopic ultrasound and MRCP are the best imaging modalities. Endoscopic ultrasound is less costly compared to ERCP and carries a lower risk of complications. If cholecystectomy is planned, choledocholithiasis can be detected by intraoperative cholangiography $[92,93,97]$.

ERCP with papillotomy is particularly useful for the removal of bile duct stones if undertaken within 24 hours of the patient being admitted. For patients with acute biliary pancreatitis and concomitant cholangitis, this approach has benefits regarding reducing both morbidity and mortality [97, 98].

Following the first episode of gallstone pancreatitis, the risk of cholecystitis or cholangitis increases, and may occur in up to $30 \%$ of patients. Cholecystectomy is advisable, and is usually performed in all operable patients after recovery $[67,82,99-101]$, even after endoscopic sphincterotomy [102]. In patients with mild pancreatitis, cholecystectomy is indicated after symptoms have subsided and laboratory tests have normalized, usually within one week and during the same hospitalization period. If the episode of acute pancreatitis is severe and necrotizing, cholecystectomy is delayed until active inflammation subsides and fluid collections have resolved or stabilized [103].

Hirota et al. (2007) also suggest that severe pancreatitis associated with ongoing multisystem organ failure is a condition requiring the immediate clearance of any biliary obstruction. Supportive care is indicated until the patient recovers sufficiently to tolerate cholecystectomy. Sometimes patients who have had an attack of acute pancreatitis and a transient elevation of serum amylase and lipase levels show no exact cause of acute pancreatitis. The presence of biliary sludge requires timely attention and, if sludge exists, cholecystectomy is recommended [104-107].

The initial care of patients with acute pancreatitis is based on:

Pain control with opioids. Intravenous infusion allows fast and optimal relief. Hydromorphone in opioid naïve is usually started at $0.2-1.0 \mathrm{mg}$ every 2 to 3 hours and then titrated as needed. Higher initial doses can be required in patients with prior opioid. Fentanyl has better safety profile. The bolus infusion is based on 20$50 \mathrm{ug}$ (with an interval of 10 min until next bolus is scheduled by the machine). The continuous infusion usually starts at a low dose. Alternatively, other modalities include the regular interval regimen or the infusion by patient control. The initial doses can be titrated until the desired effect is achieved, always checking for 
opiate-related side effects (e.g., depression of respiratory drive, CNS-depressant effects, hypotension, ileus, urinary retention, nausea and vomiting). Meperidine (initial dose 25-50 mg i.v.) has shorter half-life but puts the patients at higher risk of metabolite accumulation (neuromuscular side effects if repeated doses are used.

Fluid resuscitation: $5-10 \mathrm{~mL} / \mathrm{Kg} / \mathrm{hr}$ of isotonic crystalloid solution, with checks for cardiovascular and renal morbidities and adequate response.

Nutritional support: enteral feeding in patients who do not tolerate oral feeding).

Patients with acute pancreatitis require frequent monitoring, especially in the first $24-48 \mathrm{hrs}$. Monitoring should include testing vital signs, electrolytes, serum glucose and urine output. If an infection is suspected, therapy includes antibiotics and suture-guided medications. Prophylactic antibiotics are not recommended in patients with any type of acute pancreatitis [108].

\section{Recurrent pyogenic cholangitis}

Recurrent bouts of cholangitis are classified as recurrent pyogenic cholangitis.

Repeated inflammatory episodes can ultimately result in stricture of the biliary tree and obstruction. The obstruction often causes proximal bile stasis with recurrent cholangitis and pyogenic inflammation of bile ducts. Pyogenic cholangitis is frequent in Southeast Asia or in immigrants from that region [109]. There is a similar gender prevalence. The aetiology of pyogenic cholangitis includes parasitic infection with Clonorchis sinensis, Fasciola hepatica or Opisthorchis species, although the actual association is still debated.

Episodes of transient portal bacteremia may transfer bacteria to the biliary ducts. This condition may start a local infection and lead to stone formation and related infection and obstruction. Detected bacteria in bile include E. coli, Klebsiella, Proteus species, Pseudomonas or anaerobes.

Bile duct stasis is another predisposing factor. Bile duct strictures might also follow repeated episodes of inflammation, and the formation of intrahepatic pigment stones can be a consequence of pyogenic cholangitis. Another cause, facilitating the inflammatory process, is a defect of hepatic phospholipid transporter [110].

The diagnosis of recurrent pyogenic cholangitis relies on imaging such as abdominal ultrasound, CT scan, ERCP, MRCP, and percutaneous transhepatic cholangiography.

\section{Critical care aspects}

Clinical features of pyogenic cholangitis are extra- or intrahepatic ductal dilatation, focal stenotic areas of the intrahepatic bile ducts, development of purulent bile enriched in bile pigments and debris, bacterial concentration, and intrahepatic stones in the right and left lobes, and extrahepatic ducts.

Clinically, patients with recurrent pyogenic cholangitis are exposed to sepsis, biliary inflammation, and liver cirrhosis with an increased risk of cholangiocarcinoma [111]. The management of patients is multidisciplinary. Acute complications require intravenous fluids, antibiotics, and biliary drainage (ERCP, PTC, or surgical). The prevention of long-term complications includes stone removal or if required, surgical resection of the hepatobiliary segment, which is affected by biliary-enteric anastomosis and the clearance of stones.

\section{Acalculous cholecystitis}

Acute cholecystitis occurring in the absence of gallstones is termed acalculous cholecystitis and occurs in approximately $10 \%$ of patients with acute cholecystitis [112]. However, the ongoing acute necro-inflammatory process of the gallbladder shows greater morbidity and mortality rates in acalculous cholecystitis than in calculous cholecystitis.

\section{Critical care aspects}

Acalculous cholecystitis is frequently encountered in patients with serious medical comorbidities, i.e. patients in the ICU setting [113-119]. Predisposing factors are depicted in Figure 4 and include the critically ill patient, serious illness, drugs, chronic conditions, and surgery. The potential disease mechanisms include gallbladder stasis and ischemia, local damage of concentrated bile acids [120,121], and local inflammatory changes occurring in the gallbladder wall. Therefore, necrosis and perforation of gallbladder wall may develop. The mortality in patients with acalculous cholecystitis is related to the underlying medical and surgical conditions. The mortality rate ranges from $10 \%$ in community-acquired cases to $90 \%$ in critically ill patients $[62,112]$. 


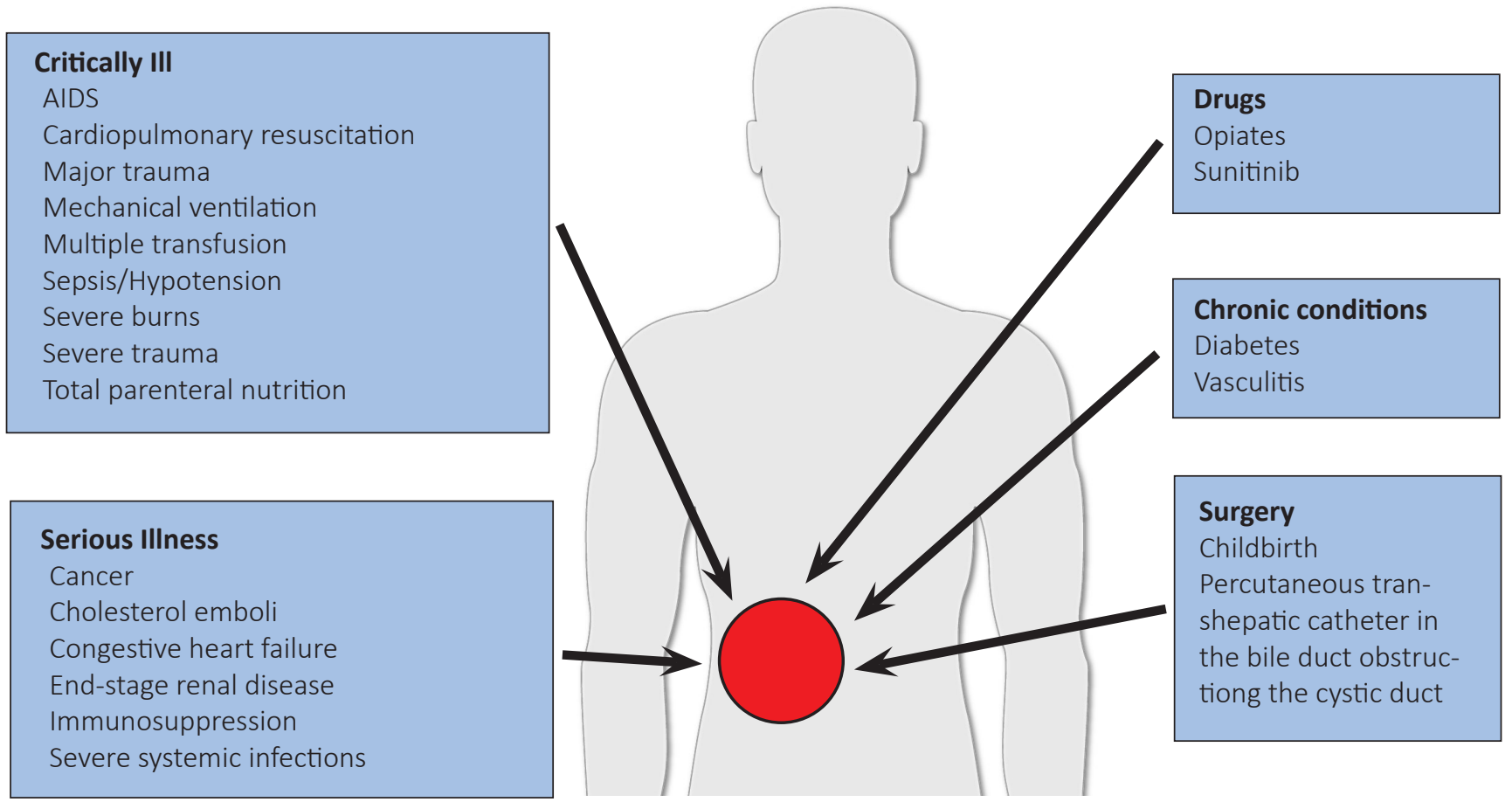

Fig. 4. Factors predisposing to acute acalculous cholecystitis.

\section{Conclusions AND PERSPECTIVES}

Due to the rise in the prevalence of metabolic abnormalities such as insulin resistance, obesity, and diabetes, the prevalence of gallstone disease is increasing worldwide. This trend occurs in both developed and developing countries and globally represents a significant financial and social burden. Although 75 to $80 \%$ of subjects with gallstones remain asymptomatic, symptoms such as biliary pain or other complications occur in about $20 \%$ of patients. These patients require immediate attention, speedy and appropriate diagnosis, and accepted therapies including medical endoscopic, and surgical treatments. Critical care aspects, which include acute cholecystitis, gallstone ileus, cholestatic jaundice, acute cholangitis, acute biliary pancreatitis, and recurrent pyogenic cholangitis, must be adequately recognised.

Several predisposing conditions exist and put patients at risk of very severe and often life-threatening complications.

\section{ACKNOWLEDGEMENTS}

The present paper is written in the context of the FOIE GRAS project, which received funding from the European Union's Horizon 2020 Research and Innovation programme under the Marie Skłodowska-Curie Grant Agreement No. 722619.

\section{CONFLICT OF INTERESTS}

None to declare

\section{REFERENCES}

1. Portincasa P, Moschetta A, Palasciano G. Cholesterol gallstone disease. Lancet. 2006;368:230-9.

2. Shabanzadeh DM. Incidence of gallstone disease and complications. Curr Opin Gastroenterol. 2018;34:81-9.

3. Farthing M, Roberts SE, Samuel DG, et al. Survey of digestive health across Europe: Final report. Part 1: The burden of gastrointestinal diseases and the organisation and delivery of gastroenterology services across Europe. United European Gastroenterol J. 2014;2:539-43.

4. Attili AF, Carulli N, Roda E, et al. Epidemiology of gallstone disease in Italy: prevalence data of the Multicenter Italian Study on Cholelithiasis (M.I.COL.). Am J Epidemiol. 1995;141:158-65.

5. Diehl AK. Epidemiology and natural history of gallstone disease. Gastroenterol Clin North Am. 1991;20:1-19.

6. Sherlock S, Dooley J. Diseases of the liver and biliary system. Oxford: Blackwell Science: 2002 pp. 597-628.

7. Trotman BW, Ostrow JD, Soloway RD. Pigment vs cholesterol cholelithiasis: comparison of stone and bile composition. Am J Dig Dis. 1974;19:585-90. 
Available online at: www.jccm.ro

8. Di Ciaula A, Garruti G, Wang DQ-H, Portincasa P. Role of insulin resistance in the formation of cholesterol gallstones. In: Wang DQ-H and Portincasa P, editors. Gallstones - Recent advances in epidemiology, pathogenesis, diagnosis and management. New York: Nova Science Publishers; 2017pp. 357-72.

9. Shabanzadeh DM, Skaaby T, Sorensen LT, Eugen-Olsen J, Jorgensen T. Metabolic biomarkers and gallstone disease - a population-based study. Scand J Gastroenterol. 2017;52:12707.

10. Barbara L, Sama C, Morselli Labate AM, et al. A population study on the prevalence of gallstone disease: the Sirmione Study. Hepatology. 1987; 7:913-7.

11. Attili AF, De Santis A, Capri R, Repice AM, Maselli S. The natural history of gallstones: the GREPCO experience. The GREPCO Group. Hepatology. 1995;21:655-60.

12. Glambek I, Kvaale G, Arnesjo B, Soreide O. Prevalence of gallstones in a Norwegian population. Scand J Gastroenterol. 1987;22:1089-94.

13. Schmidt M, Hausken T, Glambek I, Schleer C, Eide GE, Sondenaa K. A 24-year controlled follow-up of patients with silent gallstones showed no long-term risk of symptoms or adverse events leading to cholecystectomy. Scand J Gastroenterol. 2011;46:949-54.

14. Gibney EJ. Asymptomatic gallstones. Br J Surg. 1990;77:368-72.

15. Gracie WA, Ransohoff DF. The natural history of silent gallstones: the innocent gallstone is not a myth. N Engl J Med. 1982;307:798-800.

16. Friedman GD. Natural history of asymptomatic and symptomatic gallstones. Am J Surg. 1993;165:399-404.

17. Thistle JL, Cleary PA, Lachin JM, Tyor MP, Hersh T. The natural history of cholelithiasis: the National Cooperative Gallstone Study. Ann Intern Med. 1984;101:171-5.

18. Sobolev B, Mercer D, Brown P, FitzGerald M, Jalink D, Shaw R. Risk of emergency admission while awaiting elective cholecystectomy. CMAJ. 2003;169:662-5.

19. Portincasa P, Di Ciaula A, de Bari O, Garruti G, Palmieri VO, Wang $\mathrm{DQ}$. Management of gallstones and its related complications. Expert Rev Gastroenterol Hepatol. 2016;10:93-112.

20. Lammert F, Gurusamy K, Ko CW, et al. Gallstones (For the Primer, visit doi:10.1038/nrdp.2016.24). Nat Rev Dis Primers. 2016;2:16025.

21. European Association for the Study of the L. EASL Clinical Practice Guidelines on the prevention, diagnosis and treatment of gallstones. J Hepatol. 2016;65:146-81.

22. Portincasa P, Wang DQH. Gallstones. In: Podolsky KD, Camilleri M, Fitz JG, Kalloo AN, Shanahan F and Wang TC, editors. Yamada's Textbook of Gastroenterology. Hoboken, New Jersey (USA): Wiley-Blackwell; 2015. pp. 1808-34.

23. Kraag N, Thijs C, Knipschild P. Dyspepsia: how noisy are gallstones? A meta-analysis of epidemiologic studies of biliary pain, dyspeptic symptoms, and food intolerance. Scand J Gastroenterol. 1995;30:411-21.
The Journal of Critical Care Medicine 2019;(5)1 • 15

24. Gui GP, Cheruvu CV, West N, Sivaniah K, Fiennes AG. Is cholecystectomy effective treatment for symptomatic gallstones? Clinical outcome after long-term follow-up. Ann R Coll Surg Engl. 1998;80:25-32.

25. Fenster LF, Lonborg R, Thirlby RC, Traverso LW. What symptoms does cholecystectomy cure? Insights from an outcomes measurement project and review of the literature. Am J Surg. 1995;169:533-8.

26. Weinert CR, Arnett D, Jacobs D, Jr., Kane RL. Relationship between persistence of abdominal symptoms and successful outcome after cholecystectomy. Arch Intern Med. 2000;160:989-95.

27. Diehl AK, Sugarek NJ, Todd KH. Clinical evaluation for gallstone disease: usefulness of symptoms and signs in diagnosis. Am J Med. 1990;89:29-33.

28. Festi D, Sottili S, Colecchia A, Attili A, Mazzella G, Roda E et al. Clinical manifestations of gallstone disease: evidence from the multicenter Italian study on cholelithiasis (MICOL). Hepatology. 1999;30:839-46.

29. Rigas B, Torosis J, McDougall CJ, Vener KJ, Spiro HM. The circadian rhythm of biliary colic. J Clin Gastroenterol. 1990;12:409-14.

30. Minoli G, Imperiale G, Spinzi GC, Terruzzi V, Rigas B. Circadian periodicity and other clinical features of biliary pain. J Clin Gastroenterol. 1991;13:546-8.

31. Lund J. Surgical indications in cholelithiasis: prophylactic choleithiasis: prophylactic cholecystectomy elucidated on the basis of long-term follow up on 526 nonoperated cases. Ann Surg. 1960;151:153-62.

32. Berhane $T$, Vetrhus $M$, Hausken $T$, Olafsson S, Sondenaa K. Pain attacks in non-complicated and complicated gallstone disease have a characteristic pattern and are accompanied by dyspepsia in most patients: the results of a prospective study. Scand J Gastroenterol. 2006;41:93-101.

33. Schoenfield L, Carulli N, Dowling R, Sama C, Wolpers C. Asymptomatic gallstones: definition and treatment. Gastroenterol Int. 1989;2:25-9.

34. Berger MY, van dV, Lijmer JG, de KH, Prins A, Bohnen AM. Abdominal symptoms: do they predict gallstones? A systematic review. Scand J Gastroenterol. 2000;35:70-6.

35. Murphy JB. The diagnosis of gall-stones. American Medical News. 1903;82:825-33.

36. Kumar A, Deed JS, Bhasin B, Kumar A, Thomas S. Comparison of the effect of diclofenac with hyoscine-N-butylbromide in the symptomatic treatment of acute biliary colic. ANZ J Surg. 2004;74:573-6.

37. Colli A, Conte D, Valle SD, Sciola V, Fraquelli M. Meta-analysis: nonsteroidal anti-inflammatory drugs in biliary colic. Aliment Pharmacol. Ther 2012;35:1370-8.

38. Al-Waili N, Saloom KY. The analgesic effect of intravenous tenoxicam in symptomatic treatment of biliary colic: a comparison with hyoscine N-butylbromide. Eur J Med Res. 1998;3:475-9.

39. Akriviadis EA, Hatzigavriel M, Kapnias D, Kirimlidis J, Markantas A, Garyfallos A. Treatment of biliary colic with diclofenac: 
a randomized, double-blind, placebo-controlled study. Gastroenterology. 1997;113:225-31.

40. Goldman G, Kahn PJ, Alon R, Wiznitzer T. Biliary colic treatment and acute cholecystitis prevention by prostaglandin inhibitor. Dig Dis Sci. 1989;34:809-11.

41. Elta GH, Barnett JL. Meperidine need not be proscribed during sphincter of Oddi manometry. Gastrointest.Endosc. 1994;40:79.

42. Olsen JC, McGrath NA, Schwarz DG, Cutcliffe BJ, Stern JL. A double-blind randomized clinical trial evaluating the analgesic efficacy of ketorolac versus butorphanol for patients with suspected biliary colic in the emergency department. Acad Emerg Med. 2008;15:718-22.

43. Reiss R, Nudelman I, Gutman C, Deutsch AA. Changing trends in surgery for acute cholecystitis. World J Surg. 1990;14:567-70; discussion 70-1.

44. Diehl AK. Epidemiology of gallbladder cancer: a synthesis of recent data. J Natl Cancer Inst. 1980;65:1209-14.

45. Okamoto M, Okamoto $H$, Kitahara F, et al. Ultrasonographic evidence of association of polyps and stones with gallbladder cancer. Am J Gastroenterol. 1999;94:446-50.

46. Dutta U, Garg PK, Kumar R, Tandon RK. Typhoid carriers among patients with gallstones are at increased risk for carcinoma of the gallbladder. Am J Gastroenterol. 2000;95:784-7.

47. Diehl AK. Gallstone size and the risk of gallbladder cancer. JAMA. 1983;250:2323-6.

48. Shiffman ML, Sugerman HJ, Kellum JM, Brewer WH, Moore EW. Gallstone formation after rapid weight loss: a prospective study in patients undergoing gastric bypass surgery for treatment of morbid obesity. Am J Gastroenterol. 1991;86:1000-5.

49. Wattchow DA, Hall JC, Whiting MJ, Bradley B, lannos J, Watts $J M$. Prevalence and treatment of gall stones after gastric bypass surgery for morbid obesity. Br Med J (Clin Res Ed). 1983;286:763.

50. Cho JY, Han HS, Yoon YS, Ahn KS. Risk factors for acute cholecystitis and a complicated clinical course in patients with symptomatic cholelithiasis. Arch Surg. 2010;145:329-33; discussion 33.

51. Barclay AW, Petocz P, McMillan-Price J, et al. Glycemic index, glycemic load, and chronic disease risk--a meta-analysis of observational studies. Am J Clin Nutr. 2008;87:627-37.

52. Hulley S, Furberg C, Barrett-Connor E, et al. Noncardiovascular disease outcomes during 6.8 years of hormone therapy: Heart and Estrogen/progestin Replacement Study follow-up (HERS II). JAMA. 2002;288:58-66.

53. Cirillo DJ, Wallace RB, Rodabough RJ, et al. Effect of estrogen therapy on gallbladder disease. JAMA. 2005;293:330-9.

54. Hulley S, Grady D, Bush T, et al. Randomized trial of estrogen plus progestin for secondary prevention of coronary heart disease in postmenopausal women. Heart and Estrogen/ progestin Replacement Study (HERS) Research Group. JAMA. 1998;280:605-13.
55. Liu B, Beral V, Balkwill A, et al. Gallbladder disease and use of transdermal versus oral hormone replacement therapy in postmenopausal women: prospective cohort study. BMJ. 2008;337:a386.

56. Portincasa P, Wang DQH. Gallstones. In: Podolsky KD, Camilleri M, Fitz JG, Kalloo AN, Shanahan F and Wang TC, editors. Yamada's Atlas of Gastroenterology. Hoboken, New Jersey (USA): Wiley-Blackwell; 2016. pp. 335-53.

57. Carrascosa MF, Salcines-Caviedes JR. Emphysematous cholecystitis. CMAJ. 2012;184:E81.

58. Yokoe M, Takada T, Strasberg SM, et al. New diagnostic criteria and severity assessment of acute cholecystitis in revised Tokyo Guidelines. J Hepatobiliary Pancreat Sci. 2012;19:578-85.

59. Singer AJ, McCracken G, Henry MC, Thode HC, Jr., Cabahug CJ. Correlation among clinical, laboratory, and hepatobiliary scanning findings in patients with suspected acute cholecystitis. Ann Emerg Med. 1996;28:267-72.

60. Hirota M, Takada T, Kawarada Y, et al. Diagnostic criteria and severity assessment of acute cholecystitis: Tokyo Guidelines. J Hepatobiliary Pancreat Surg. 2007;14:78-82.

61. Miura F, Takada T, Strasberg SM, et al. TG13 flowchart for the management of acute cholangitis and cholecystitis. J Hepatobiliary Pancreat Sci. 2013;20:47-54.

62. Barie PS, Eachempati SR. Acute acalculous cholecystitis. Gastroenterol Clin North Am. 2010;39:343-57.

63. Mayumi T, Takada T, Kawarada Y, et al. Results of the Tokyo Consensus Meeting Tokyo Guidelines. J Hepatobiliary Pancreat Surg. 2007;14:114-21.

64. Yoshida M, Takada T, Kawarada Y, et al. Antimicrobial therapy for acute cholecystitis: Tokyo Guidelines. J Hepatobiliary Pancreat Surg. 2007;14:83-90.

65. Miura F, Takada T, Kawarada Y, et al. Flowcharts for the diagnosis and treatment of acute cholangitis and cholecystitis: Tokyo Guidelines. J Hepatobiliary Pancreat Surg. 2007;14:27-34.

66. Society of American Gastrointestinal and Endoscopic Surgeons (SAGES). SAGES guidelines for the clinical application of laparoscopic biliary tract surgery. National Guideline Clearinghouse (NCG-7855). Available at: http://www.guideline. gov/content.aspx?id=16258\&search=laparoscopic. 2010:1-37.

67. Overby DW, Apelgren KN, Richardson W, Fanelli R, Society of American G, Endoscopic S. SAGES guidelines for the clinical application of laparoscopic biliary tract surgery. Surg Endosc. 2010;24:2368-86.

68. Gurusamy KS, Davidson C, Gluud C, Davidson BR. Early versus delayed laparoscopic cholecystectomy for people with acute cholecystitis. Cochrane Database Syst Rev. 2013;6:CD005440.

69. Riall TS, Zhang D, Townsend CM, Jr., Kuo YF, Goodwin JS. Failure to perform cholecystectomy for acute cholecystitis in elderly patients is associated with increased morbidity, mortality, and cost. J Am Coll Surg. 2010;210:668-77, 77-9.

70. Zafar SN, Obirieze A, Adesibikan B, Cornwell EE, 3rd, Fullum TM, Tran DD. Optimal time for early laparoscopic cholecystectomy for acute cholecystitis. JAMA. Surg 2015;150:129-36. 
Available online at: www.jccm.ro

71. Gutt CN, Encke J, Koninger J, et al. Acute cholecystitis: early versus delayed cholecystectomy, a multicenter randomized trial (ACDC study, NCT00447304). Ann Surg. 2013;258:385-93.

72. Reisner RM, Cohen JR. Gallstone ileus: a review of 1001 reported cases. Am Surg. 1994;60:441-6.

73. Rius M, Nies AT, Hummel-Eisenbeiss J, Jedlitschky G, Keppler D. Cotransport of reduced glutathione with bile salts by MRP4 (ABCC4) localized to the basolateral hepatocyte membrane. Hepatology. 2003;38:374-84.

74. Alberti-Flor JJ, Iskandarani M, Jeffers L, Schiff ER. Mirizzi syndrome. Am J Gastroenterol. 1985;80:822-3.

75. Wada K, Takada T, Kawarada Y, et al. Diagnostic criteria and severity assessment of acute cholangitis: Tokyo Guidelines. J Hepatobiliary Pancreat Surg. 2007;14:52-8.

76. Kiriyama S, Takada T, Strasberg SM, et al. New diagnostic criteria and severity assessment of acute cholangitis in revised Tokyo Guidelines. J Hepatobiliary Pancreat Sci. 2012;19:548-56.

77. Solomkin JS, Mazuski JE, Baron EJ, Sawyer RG, Nathens AB, DiPiro JT et al. Guidelines for the selection of anti-infective agents for complicated intra-abdominal infections. Clin Infect Dis. 2003;37:997-1005.

78. Poon RT, Liu CL, Lo CM, et al. Management of gallstone cholangitis in the era of laparoscopic cholecystectomy. Arch Surg. 2001;136:11-6.

79. Sekimoto M, Takada T, Kawarada Y, et al. Need for criteria for the diagnosis and severity assessment of acute cholangitis and cholecystitis: Tokyo Guidelines. J Hepatobiliary Pancreat Surg. 2007;14:11-4.

80. Shimada H, Nakagawara G, Kobayashi M, Tsuchiya S, Kudo T, Morita S. Pathogenesis and clinical features of acute cholangitis accompanied by shock. Jpn J Surg. 1984;14:269-77.

81. Lai EC, Tam PC, Paterson IA, et al. Emergency surgery for severe acute cholangitis. The high-risk patients. Ann Surg. 1990;211:55-9.

82. Forsmark CE, Baillie J, Practice AGAIC, Economics C, Board AGAIG. AGA Institute technical review on acute pancreatitis. Gastroenterology. 2007;132:2022-44.

83. Spanier BW, Dijkgraaf MG, Bruno MJ. Epidemiology, aetiology and outcome of acute and chronic pancreatitis: An update. Best Pract Res Clin Gastroenterol. 2008;22:45-63.

84. Venneman NG, Renooij W, Rehfeld JF, et al. Small gallstones, preserved gallbladder motility, and fast crystallization are associated with pancreatitis. Hepatology. 2005;41:738-46.

85. Lerch MM, Saluja AK, Runzi M, Dawra R, Saluja M, Steer $\mathrm{ML}$. Pancreatic duct obstruction triggers acute necrotizing pancreatitis in the opossum. Gastroenterology. 1993;104:85361.

86. American Gastroenterological Association Institute on "Management of Acute Pancreatits" Clinical P, Economics C, Board AGAIG. AGA Institute medical position statement on acute pancreatitis. Gastroenterology. 2007;132:2019-21.

87. Yadav D, Agarwal N, Pitchumoni CS. A critical evaluation of
The Journal of Critical Care Medicine 2019;(5)1 • 17

laboratory tests in acute pancreatitis. Am J Gastroenterol. 2002;97:1309-18.

88. Wang SS, Lin XZ, Tsai $Y T$, et al. Clinical significance of ultrasonography, computed tomography, and biochemical tests in the rapid diagnosis of gallstone-related pancreatitis: a prospective study. Pancreas. 1988;3:153-8.

89. Neoptolemos JP, Hall AW, Finlay DF, Berry JM, Carr-Locke DL, Fossard DP. The urgent diagnosis of gallstones in acute pancreatitis: a prospective study of three methods. Br J Surg. 1984;71:230-3.

90. Tenner S, Dubner H, Steinberg W. Predicting gallstone pancreatitis with laboratory parameters: a meta-analysis. Am J Gastroenterol. 1994;89:1863-6.

91. Chang L, Lo SK, Stabile BE, Lewis RJ, de Virgilio C. Gallstone pancreatitis: a prospective study on the incidence of cholangitis and clinical predictors of retained common bile duct stones. Am J Gastroenterol. 1998;93:527-31.

92. Committee ASoP, Gan SI, Rajan E, et al. Role of EUS. Gastrointest Endosc. 2007;66:425-34.

93. Mesenas S, Ang TL, Khor C, Vu C. Guidelines for endoscopic ultrasonography. Ann Acad Med Singapore. 2010;39:489-92.

94. Hallal AH, Amortegui JD, Jeroukhimov IM, et al. Magnetic resonance cholangiopancreatography accurately detects common bile duct stones in resolving gallstone pancreatitis. J Am Coll Surg. 2005;200:869-75.

95. Kim YJ, Kim MJ, Kim KW, et al. Preoperative evaluation of common bile duct stones in patients with gallstone disease. AJR Am J Roentgenol. 2005;184:1854-9.

96. Moon JH, Cho YD, Cha SW, et al. The detection of bile duct stones in suspected biliary pancreatitis: comparison of MRCP, ERCP, and intraductal US. Am J Gastroenterol. 2005;100:10517.

97. Committee ASoP, Maple JT, Ben-Menachem T, et al. The role of endoscopy in the evaluation of suspected choledocholithiasis. Gastrointest Endosc. 2010;71:1-9.

98. Working Group IAPAPAAPG. IAP/APA evidence-based guidelines for the management of acute pancreatitis. Pancreatology. 2013;13:e1-15.

99. Hernandez V, Pascual I, Almela P, et al. Recurrence of acute gallstone pancreatitis and relationship with cholecystectomy or endoscopic sphincterotomy. Am J Gastroenterol. 2004;99:2417-23.

100. Yadav D, O'Connell M, Papachristou GI. Natural history following the first attack of acute pancreatitis. Am J Gastroenterol. 2012;107:1096-103.

101. Banks PA, Freeman ML, Practice Parameters Committee of the American College of $\mathrm{G}$. Practice guidelines in acute pancreatitis. Am J Gastroenterol. 2006;101:2379-400.

102. Laws HL, Kent RB, 3rd. Acute pancreatitis: management of complicating infection. Am Surg. 2000;66:145-52.

103. Uhl W, Muller CA, Krahenbuhl L, Schmid SW, Scholzel $\mathrm{S}$, Buchler MW. Acute gallstone pancreatitis: timing of 
18 - The Journal of Critical Care Medicine 2019;5(1)

laparoscopic cholecystectomy in mild and severe disease. Surg Endosc. 1999;13:1070-6.

104. Ko CW, Sekijima JH, Lee SP. Biliary sludge. Ann Intern Med. 1999;130:301-11.

105. Ros E, Navarro S, Bru C, Garcia-Puges A, Valderrama R. Occult microlithiasis in 'idiopathic' acute pancreatitis: prevention of relapses by cholecystectomy or ursodeoxycholic acid therapy. Gastroenterology. 1991;101:1701-9.

106. Aboulian A, Chan T, Yaghoubian A, et al. Early cholecystectomy safely decreases hospital stay in patients with mild gallstone pancreatitis: a randomized prospective study. Ann Surg. 2010;251:615-9.

107. Moraes JM, Felga GE, Chebli LA, et al. A full solid diet as the initial meal in mild acute pancreatitis is safe and result in a shorter length of hospitalization: results from a prospective, randomized, controlled, double-blind clinical trial. J Clin Gastroenterol. 2010;44:517-22.

108. Crockett SD, Wani S, Gardner TB, Falck-Ytter Y, Barkun AN, American Gastroenterological Association Institute Clinical Guidelines C. American Gastroenterological Association Institute Guideline on Initial Management of Acute Pancreatitis. Gastroenterology. 2018;154:1096-101.

109. Nakayama F, Soloway RD, Nakama T, et al. Hepatolithiasis in East Asia. Retrospective study. Dig Dis Sci. 1986;31:21-6.

110. Shoda J, Inada $Y$, Osuga T. Molecular pathogenesis of hepatolithiasis--a type of low phospholipid-associated cholelithiasis. Front Biosci. 2006;11:669-75.

111. Jan YY, Chen MF, Wang CS, Jeng LB, Hwang TL, Chen SC. Surgical treatment of hepatolithiasis: long-term results. Surgery. 1996;120:509-14.

112. Kalliafas S, Ziegler DW, Flancbaum L, Choban PS. Acute acalculous cholecystitis: incidence, risk factors, diagnosis, and outcome. Am Surg. 1998;64:471-5.

113. Shapiro MJ, Luchtefeld WB, Kurzweil S, Kaminski DL, Durham RM, Mazuski JE. Acute acalculous cholecystitis in the critically ill. Am Surg. 1994;60:335-9.

114. Gofrit O, Eid A, Pikarsky A, Lebensart PD, Pizov G, Rivkind A. Cholesterol embolisation causing chronic acalculous cholecystitis. Eur J Surg. 1996;162:243-5.

115. Schwesinger WH, Diehl AK. Changing indications for
Available online at: www.jccm.ro

laparoscopic cholecystectomy. Stones without symptoms and symptoms without stones. Surg Clin North Am. 1996;76:493504.

116. Wiboltt KS, Jeffrey RB, Jr. Acalculous cholecystitis in patients undergoing bone marrow transplantation. Eur J Surg. 1997;163:519-24.

117. Romero Ganuza FJ, La Banda G, Montalvo R, Mazaira J. Acute acalculous cholecystitis in patients with acute traumatic spinal cord injury. Spinal Cord. 1997;35:124-8.

118. Nash JA, Cohen SA. Gallbladder and biliary tract disease in AIDS. Gastroenterol Clin North Am. 1997;26:323-35.

119. McChesney JA, Northup PG, Bickston SJ. Acute acalculous cholecystitis associated with systemic sepsis and visceral arterial hypoperfusion: a case series and review of pathophysiology. Dig Dis Sci. 2003;48:1960-7.

120. Di Ciaula A, Wang DQ, Molina-Molina E, et al. Bile Acids and Cancer: Direct and Environmental-Dependent Effects. Ann Hepatol. 2017;16:s87-s105.

121. Di Ciaula A, Garruti G, Lunardi Baccetto R, et al. Bile Acid Physiology. Ann Hepatol. 2017;16:s4-s14.

122. Shea JA, Berlin JA, Escarce JJ, et al. Revised estimates of diagnostic test sensitivity and specificity in suspected biliary tract disease. Arch Intern Med. 1994;154:2573-81.

123. Kiewiet JJ, Leeuwenburgh MM, Bipat S, Bossuyt PM, Stoker J, Boermeester MA. A systematic review and meta-analysis of diagnostic performance of imaging in acute cholecystitis. Radiology. 2012;264:708-20.

124. Bingener J, Schwesinger $\mathrm{WH}$, Chopra S, Richards ML, Sirinek KR. Does the correlation of acute cholecystitis on ultrasound and at surgery reflect a mirror image? Am J Surg. 2004;188:703-7.

125. Fidler J, Paulson EK, Layfield L. CT evaluation of acute cholecystitis: findings and usefulness in diagnosis. AJR Am J Roentgenol. 1996;166:1085-8.

126. Shakespear JS, Shaaban AM, Rezvani M. CT findings of acute cholecystitis and its complications. AJR Am J Roentgenol. 2010;194:1523-9.

127. Park MS, Yu JS, Kim YH, et al. Acute cholecystitis: comparison of MR cholangiography and US. Radiology. 1998;209:781-5. 